\title{
Management of Benign Prostatic Hyperplasia: Could Dietary Polyphenols Be an Alternative to Existing Therapies?
}

\author{
Chinedum Eleazu ${ }^{1 *}$ Kate Eleazu² and Winner Kalu \\ 'Department of Chemistry/Biochemistry, Federal University Ndufu-Alike, Ikwo, Abakaliki, Nigeria, ${ }^{2}$ Department of \\ Biochemistry, Ebonyi State University, Abakaliki, Nigeria, ${ }^{3}$ Department of Biochemistry, Michael Okpara University of \\ Agriculture, Umudike, Nigeria
}

\section{OPEN ACCESS}

Edited by:

Cesare Mancuso,

Università Cattolica del Sacro Cuore,

Italy

Reviewed by:

Daniela Giacomazza,

Consiglio Nazionale Delle Ricerche

(CNR), Italy

Stanislav Yanev,

Institute of Neurobiology (BAS),

Bulgaria

${ }^{*}$ Correspondence:

Chinedum Eleazu

eleazon@yahoo.com

Specialty section:

This article was submitted to Drug Metabolism and Transport,

a section of the journal

Frontiers in Pharmacology

Received: 02 March 2017

Accepted: 12 April 2017

Published: 28 April 2017

Citation:

Eleazu C, Eleazu K and Kalu W

(2017) Management of Benign

Prostatic Hyperplasia: Could Dietary

Polyphenols Be an Alternative

to Existing Therapies?

Front. Pharmacol. 8:234

doi: 10.3389/fphar.2017.00234
The incidence of benign prostatic hyperplasia $(\mathrm{BPH})$ is gradually on the increase. While conventional drugs such as the $\alpha 1$-adrenergic receptor antagonists and $5 \alpha$-reductase inhibitors have been found to be useful in the treatment of $\mathrm{BPH}$, the adverse side effects associated with their usage, have led to increased search for alternative means of managing this disease. Furthermore, although surgery has also been suggested to be a sure method, the cost and risks associated with it excludes it as a routine treatment. Dietary polyphenols have gained public interest in recent times due to their roles in the prevention of various diseases that implicate free radicals/reactive oxygen species. However, their roles in the management of BPH have not been explored. Hence, this review on their prospects in the management of $\mathrm{BPH}$ and their mechanisms of action. Literature search was carried out in several electronic data bases such as PubMed, Google Scholar, Medline, Agora, and Hinari from1970 to 2017 to identify the current status of knowledge on this concept. The findings from these data bases suggest that while dietary polyphenols may not replace the need for the existing therapies in the management of $\mathrm{BPH}$, they hold promise in $\mathrm{BPH}$ management which could be explored by researchers working in this field.

Keywords: benign prostatic hyperplasia, polyphenols, nutrition, antioxidants, nutraceuticals

\section{INTRODUCTION}

Benign prostatic hyperplasia (BPH) is the most common urological condition among elderly men, affecting approximately half of men over 80 years of age. It usually begins as a simple micronodular hyperplasia with a subsequent macroscopic nodular enlargement that may result in bladder outlet obstruction and the development of lower urinary tract symptoms (LUTS) (Aleksandra et al., 2015).

As the prostate enlarges, it constricts the urethra, inducing various symptoms such as: weak urinary stream, incomplete bladder emptying, nocturia, dysuria, and bladder outlet obstruction (In et al., 2012). These symptoms which have been associated with BPH are known as LUTS (Barkin, 2011).

Although the molecular and stromal mechanisms associated with the pathogenesis of this metabolic disorder have not yet been fully elucidated (Aleksandra et al., 2015), several factors such as: inflammatory mediators, hormonal, dietary factors, environmental and oxidative stress have been implicated in its etiology (Minciullo et al., 2015).

Currently, the two major medications that are being used for the treatment of BPH include the $\alpha 1$-adrenergic receptor antagonists (doxazosin, terazosin, and tamsulosin) which alleviate 
LUTS by relaxation of smooth muscle in the prostate and the neck of the bladder; and the $5 \alpha$-reductase inhibitors [which inhibit the development of $\mathrm{BPH}$ through a reduction in dihydrotestosterone (DHT) production].

While these conventional drugs have been found to be efficacious in the treatment of $\mathrm{BPH}$, the adverse effects associated with them, ranging from impotence and gynaecomastia to orthostatic hypotension, abnormal ejaculation amongst others, have led to increased search for alternative means of managing this disease.

Although surgery has also been suggested to be an option, the cost and risks associated with it excludes it as a routine treatment. The trend then is increased search for alternative methods of managing this disease using natural remedies (Kalu W. et al., 2016; Kalu W.O. et al., 2016).

Polyphenols are the most abundant dietary antioxidants and are common constituents of many plant food sources, including fruits, vegetables, seeds, nuts, chocolate, wine, coffee, and tea. Natural polyphenols have increasingly gained public interest in recent times. This could be attributed to the emerging evidence that suggests their roles in the prevention of various disease that implicate free radicals/reactive oxygen species (ROS; Scalbert et al., 2005; Eleazu et al., 2013a,b, 2017). However, the role of these polyphenols in the management of $\mathrm{BPH}$ and their mechanisms of action are yet to be reported. Hence, this article which reviewed the concept of management of BPH using dietary polyphenols.

\section{MATERIALS AND METHODS}

Literature search was carried out in several electronic data bases such as PubMed, Google Scholar, Medline, Agora, and Hinari from 1970 to 2017 to identify the current status of knowledge on the contribution of dietary polyphenols to the management of $\mathrm{BPH}$ and their mechanisms of action. The findings from these data bases are therefore reported in this review.

\section{Definition of Polyphenols}

Polyphenol is a generic term for thousands of plant-based molecules that possess antioxidant properties. These polyphenols have been identified as secondary metabolites of plants that contain one or more hydroxyl groups attached to the ortho, meta or para positions on a benzene ring (Rajasekaran et al., 2001).

Over 8,000 identified polyphenols are present in foods and they have been found to play important roles in the maintenance of human health and wellness (Tsao, 2010; Eleazu et al., 2013b; Eleazu, 2016).

\section{Classification of Polyphenols and Their Dietary Sources}

Polyphenols could be classified into five groups namely: (a) phenolic acids, (b) stilbenes, (c) lignans (d) flavonoids, and (e) curcuminoids (Eleazu and Eleazu, 2015; Ly et al., 2015; Eleazu et al., 2017). (a) Phenolic acids are further divided into two subgroups which are: (i) hydroxybenzoic acids (example is gallic acid), found in tea and (ii) hydroxycinnamic acids. Examples of hydroxycinnamic acids are caffeic acid found in virtually all fruits (Manach and Donovan, 2004); chlorogenic acid found in strawberries, pineapple, etc; and p-coumaric acid that is found in cereal grains (Ly et al., 2015).

(b) Stilbenes are found in red wines, red grape juice and peanuts (Vitrac et al., 2002; Prasad, 2012) while resveratrol is the most common.

(c) Lignans: These groups of polyphenols include: secoisolariciresinol found in flaxseed (Ly et al., 2015) and sesamin found in sesame seed (Smeds et al., 2012).

(d) Flavonoids could be found in fruits, vegetables, legumes, red wine, and green tea. They are further divided into eight subgroups namely: flavanols, flavonols, flavones, isoflavones, flavanones, anthocyanins, proanthocyanidins, and chalcones. Flavanols (example is epigallocatechin gallate) are found in green and black tea (Khan and Mukhtar, 2007).

Flavonols (examples are kaempferol and quercetin) could be found in onions, broccoli, and blueberries (Hollman and Arts, 2000).

Anthocyanins (example is cyanin glucoside) could be found in highly pigmented fruits (Ly et al., 2015).

Flavones (examples include: apigenin, chrysin, and luteolin) could be found in Parsley and Celery (Ly et al., 2015).

Isoflavones (examples are daidzein and genistein) are found in soya and its processed products (Cassidy et al., 2000).

Flavanones (example is naringenin) could be found in grapefruit (Ly et al., 2015).

Chalcones are mainly abundant in beer. They are also abundant in fruits like citruses and apples; in certain vegetables such as shallot, tomatoes, potatoes, and bean sprouts and in various plants and spices (licorice, cardamom). Xanthohumol is the main prenylated chalcone, predominately found in beer (Mojzer et al., 2016; Eleazu et al., 2017).

(e) Curcuminoids represent another class of polyphenols; a typical example being curcumin which is found in Curcuma longa (Eleazu et al., 2017).

\section{Metabolism, Absorption, and Bioavailability of Polyphenols}

After metabolism of polyphenols by Phase I and II enzymes of xenobiotic metabolism, weakly conjugated polyphenols reenter circulation, while extensively conjugated polyphenols are excreted in the bile and enter the large intestine. The microflora hydrolyzes glycosides into aglycones and then metabolizes the aglycones into different aromatic acids, which are well absorbed across the colonic barrier (Han et al., 2007; Knaup et al., 2007; Eleazu et al., 2017).

The physicochemical properties of polyphenols (such as: molecular weight, extent of glycosylation and esterification) determine their intestinal absorption (Eleazu et al., 2017). Polyphenols in the form of esters and glycosides are absorbed less rapidly and less efficiently than aglycones and 
glucosides (Manach and Donovan, 2004) due to the fact that glycosylated polyphenols are hydrophilic and thus are unable to passively diffuse through the gut wall until they are hydrolyzed (Nemeth et al., 2003; Mojzer et al., 2016). This provides an explanation for the low absorption of dietary polyphenols in the stomach as most of them are mostly present in glycosylated forms with one or more sugar residues conjugated to a hydroxyl group or the aromatic ring.

While the actual bioavailability of dietary polyphenols is yet to be fully understood, there are indications that the prostate gland is one of the tissues that readily incorporate them (Eleazu et al., 2017). For instance, studies carried out by Abd et al. (2006) indicated that polyphenols were detected by HPLC technique in a number of tissues in mice and rats, one of which is the prostate, suggesting their bioavailability in the prostatic tissue. In another study (Henning et al., 2006) that investigated the bioavailability of tea polyphenols and theaflavins in human serum and human and mouse tissues, these polyphenols were found in the conjugated and free forms in the prostate tissue in addition to other tissues. These reports thus suggest the prostate gland to be one of the tissues where dietary polyphenols exert their biological actions.

\section{ETIOLOGY OF BPH}

Benign prostatic hyperplasia is a major health concern and which incidence is expected to increase in line with the greater life expectancy. A number of factors have been implicated in its etiology and which factors include: aging, hormonal alterations, metabolic syndrome, inflammation, oxidative stress (Roehrborn and McConnell, 2002), and more recently, suppression of apoptosis in the prostatic tissue.

\section{Aging and BPH}

Aging has been implicated as the major risk factor for the development of BPH (Roehrborn and McConnell, 2002; Aleksandra et al., 2015). Several studies have demonstrated a relationship between age and markers of $\mathrm{BPH}$ progression (Neuhouser et al., 2008; Liu et al., 2009).

In aging males, tissue remodeling occurs within the prostate especially in the transition zone. The most significant modifications occur in the basal cells which change their intracellular metabolism leading to prostatic enlargement. The nodular enlargement is androgen dependent and the tissue remodeling involves both the epithelium and fibromuscular stroma (Kalu W. et al., 2016; Kalu W.O. et al., 2016).

\section{Hormonal Alteration and BPH}

The growth and malignant transformation of the prostate gland have been reported to be influenced by sex hormone levels. Although androgens do not cause $\mathrm{BPH}$, the development of $\mathrm{BPH}$ requires the presence of testicular androgens during prostate development, puberty, and aging (Kalu W.O. et al., 2016). Reports also have it that bioavailable prostatic testosterone levels decline with age (Alberto et al., 2009).
Luminal secretory cells require androgens, especially the intracellular metabolite of testosterone, DHT, for terminal differentiation and secretory functions. Testosterone is converted to DHT by the intracellular enzyme, $5 \alpha$ reductase type 2 (Roehrborn and McConnell, 2002; Alberto et al., 2009; Aleksandra et al., 2015) which is located on the prostatic nuclear membrane for both the stroma and the epithelium (Roehrborn and McConnell, 2002; Aleksandra et al., 2015).

Dihydrotestosterone can act in an autocrine fashion on the stromal cells or in paracrine fashion by diffusing into nearby epithelial cells. In both of these cell types, DHT binds to nuclear androgen receptors and signals the transcription of growth factors that are mitogenic to the epithelial and stromal cells leading to prostatic hyperplasia. DHT is ten times more potent than testosterone because it dissociates from the androgen receptor more slowly. The importance of DHT in causing nodular hyperplasia is supported by clinical observations in which finasteride, an inhibitor of $5 \alpha$-reductase is given to men with BPH. Therapeutic use of the $5 \alpha$-reductase inhibitors markedly reduces the DHT content of the prostate and, in turn, reduces prostate volume and $\mathrm{BPH}$ symptoms (Alberto et al., 2009).

There are indications that estrogens may also contribute to the etiology of BPH (Kalu W.O. et al., 2016). Reports have it that as men age, their testicular function decreases as are their androgen levels. Furthermore, the conversion of androgen to estrogen is increased (Zhou et al., 2010). In addition, while circulating levels of free estradiol remain constant in the aging man due to an age-related increase in body weight and adipose cells, the increase in the adipose cells leads to the expression of high levels of aromatase that produces estrogen conversion. The result is that the plasma estrogen to androgen ratio increases, resulting in decreased inhibition of androgens on estrogen release. The released estrogens cause increased stimulation of the prostatic stroma, resulting in excessive proliferation of the prostate and occurrence of BPH (Alberto et al., 2009; Ho and Habib, 2011; Kalu W.O. et al., 2016). Estrogen induced stimulation of prostatic growth has also been reported in dogs and monkeys (Jeyaraj et al., 2000; Roehrborn and McConnell, 2002; Aleksandra et al., 2015).

\section{BPH and Metabolic Syndrome}

Metabolic syndrome is a well-recognized cluster of cardiovascular risk factors including obesity, hypertension, dyslipidemia, and hyperglycemia, closely associated with an increased risk of cardiovascular diseases (Corona et al., 2014).

Hammarsten and Högstedt (2001) in their studies reported that patients with hypertension, and obesity were at risk of developing BPH. Epidemiologic studies also provided evidence that hypertensive men are more likely to develop BPH and to undergo medical and surgical therapy than healthy men (McVary, 2006). These studies hypothesized that the noradrenergic nerves may contribute to the functional component of the bladder outlet obstruction due to $\mathrm{BPH}$.

Recent studies (Aleksandra et al., 2015) also confirmed the frequent coexistence of metabolic syndrome and BPH. This association was suggested by the authors to be a result of the 
metabolic syndrome-related metabolic derangements, changes in the sex-hormone and lowered sex-hormone binding protein levels.

\section{BPH and Oxidative Stress}

Oxidative stress refers to an imbalance between the production and detoxification of ROS/free radicals in favor of ROS/free radicals that can cause tissue damage (Eleazu et al., 2013b, 2017; Minciullo et al., 2015).

Reactive nitrogen species (RNS) and ROS are by-products of normal cellular metabolism which impact on cell signaling. Increases in the levels of these ROS and RNS induce oxidative stress (Udensi and Paul, 2016) by causing a significant decrease in antioxidant defense mechanisms, leading to protein, lipid and DNA damage and subsequent disruption of cellular functions and cell death.

Oxidative stress has been considered to be one of the mechanisms that trigger the chain of reactions involved in the development and progression of prostatic hyperplasia. This is especially true as the human prostate tissue is vulnerable to oxidative DNA damage due to more rapid cell turnover and fewer DNA repair enzymes (Minciullo et al., 2015).

Recent studies carried out by Udensi and Paul (2016), showed the levels of antioxidants in the prostatic tissue to be significantly decreased in prostatic hyperplasia (Udensi and Paul, 2016). Furthermore, our study (Kalu W. et al., 2016) on animal models of BPH showed significant elevation of prostatic lipid peroxidation with concomitant significant reduction of the prostatic levels of GSH, SOD, GPx, and catalase activities of $\mathrm{BPH}$ untreated rats and which parameters were significantly improved following treatment with finasteride or kolaviron.

\section{BPH and Inflammation}

Inflammation is a natural defense mechanism against pathogens and it is associated with many pathogenic diseases such as microbial and viral infections, exposure to allergens, radiation and toxic chemicals, autoimmune and chronic diseases, obesity, consumption of alcohol, tobacco use, etc. (Tarique et al., 2016).

Previous studies on the pathogenesis of BPH indicated the differential expression of cytokines in $\mathrm{BPH}$ tissue suggesting a role of inflammation in the development of BPH (Lee and Peehl, 2004). Clinical studies carried out also support the role of inflammation in BPH. For instance, Di Silverio et al. (2003) when analyzing the clinical and pathologic data of approximately 4000 patients who had undergone transurethral resection of the prostate or open prostatectomy for $\mathrm{BPH}$, found evidence of acute or chronic inflammation in $42.5 \%$ of the patients. Their studies showed a statistical significant correlation between prostate size and both acute and chronic inflammation, with neuthrophic or mononuclear infiltrates present in $29.9,37.3$, and $50 \%$ of the prostates, respectively. Other reports also correlated the degree of inflammation in patients with $\mathrm{BPH}$ with the prostatic size (Mishra et al., 2007; Nickel et al., 2008; Hamid et al., 2011).

Inflammation is also one of such ways of generating free radicals/ROS in the prostatic tissue. Prostatic inflammation can cause the generation of free radicals/oxygen species such as inducible nitric oxide synthase (iNOS), reactive nitric species and ROS (Hamid et al., 2011). For instance, while iNOS is not detected in normal prostate, it is expressed in the prostate of all BPH patients (Minciullo et al., 2015).

Prostaglandins represent a group of inflammatory mediators that result from the conversion of arachidonic acid mediated by two different isoforms of cyclooxygenase (COX) (COX-1 and COX-2), both of which forms are expressed in the prostate gland (Altavilla et al., 2012).

Cyclooxygenase-2 is a pro-inflammatory, inducible enzyme whose production is triggered by mitogens, cytokines, ROS, and growth factors in different cell types. Increased expression of COX-2 mRNA has been reported in BPH (Kirschenbaum et al., 2000; Altavilla et al., 2012). Several mechanisms have been proposed to explain the role of COX-2 in prostatic hyperplasia and one of which mechanisms involves COX-2mediated increases in prostaglandin synthesis, especially of prostaglandin E2.

In rodent models, induced prostatic inflammation was also shown to contribute to prostatic hyperplasia (Kessler et al., 1998; Hamid et al., 2011). These studies amongst others (Kramer et al., 2007; Sciarra et al., 2008; Kroeger et al., 2013) are pointers to the contribution of inflammation to the development of $\mathrm{BPH}$.

\section{BPH and Apoptosis}

Apoptosis plays an important role in the control of cell growth and in the maintenance of tissue homeostasis (Minutoli et al., 2014).

There are indications that the apoptosis machinery could be a promising therapeutic target for $\mathrm{BPH}$. This is because cell growth arises from either increased cell proliferation or decreased cell death (Alberto et al., 2009) and BPH has been shown to result from smooth muscle and epithelial proliferation primarily within the prostatic transition zone that can produce LUTS (Minutoli et al., 2014).

After physiologic growth to adult size, the prostate enters a maintenance phase, where prostatic cell proliferation occurs at a daily rate of $1-2 \%$ counter balanced by an equal rate of programmed cell death (Shariat et al., 2005). A lack of this balancing has been implicated in the development of BPH (Kyprianou, 2003; Giacomo et al., 2006).

Several studies suggested that a reduction of apoptosis might occur in BPH. For instance, the study carried out by Kyprianou et al. (1996) showed that basal and luminal epithelial cells in BPH over-express Bcl-2 (apoptotic suppressor), compared to healthy prostate tissue.

Another study also showed that survivin, an inhibitor of apoptosis that counteracts cell death and controls mitotic progression was over expressed in the stromal compartment of patients with BPH (Shariat et al., 2005).

Investigation into the mechanisms of action of the drugs that are currently being used in BPH management suggested possible interactions with apoptotic mechanisms (Giacomo et al., 2006). For example, previous studies on rat prostates showed that finasteride induced apoptosis in epithelial cells, inhibiting 
insulin-like growth factors (IGF) I and 1R expressions (Huynh et al., 1998). These authors also showed that finasteride downregulated the expression of the anti-apoptotic proteins- Bcl$\mathrm{xL}$ and $\mathrm{Bcl}-2$, making the prostate cells more susceptible to apoptosis. Other studies on $\mathrm{BPH}$ patients treated with finasteride further affirmed the pro-apoptotic effect of finasteride on the epithelial cells (Saez et al., 1998), and increased expression of the pro-apoptotic proteins (Caspases-3, -6, and -9) during finasteride treatment of BPH (Aline et al., 2005). Recent studies also showed increased expression of inhibitors of apoptosis proteins in human prostates with BPH (Rodriguez-Berriguete et al., 2010; Minutoli et al., 2014).

\section{DIETARY POLYPHENOLS AND INFLAMMATION}

Inflammation is an immunological defense mechanism by which tissues respond to an insult (Ly et al., 2015). A number of polyphenols such as resveratrol, curcumin, catechins, and others have been extensively investigated as anti-inflammatory agents (Hatcher et al., 2008). In addition, anti-inflammatory activities of other polyphenols such as quercetin, rutin, morin, hesperetin, and hesperidin have been reported in acute and chronic inflammation in animals (Aruna et al., 2014; Yang and Lim, 2014; Tarique et al., 2016).

Polyphenols have been reported to exert their antiinflammatory properties at multiple levels, through the modulation of mitogen-activated protein kinases (MAPK) signaling pathways and NF- $\mathrm{KB}$ and AP-1 transcription factors, inhibition of the production of inflammatory cytokines and chemokines, suppressing the activity of COX-2 and iNOS (Donnelly et al., 2004), thereby decreasing the production of ROS/RNS (Ichikawa et al., 2004; Pandey and Rizvi, 2009).

\section{DIETARY POLYPHENOLS AND OXIDATIVE STRESS}

Oxidative stress occurs when there is an imbalance between the pro-oxidants and the antioxidants in a cell system in favor of the pro-oxidants which can result in damage to DNA, proteins and lipids as earlier defined.

Consumption of polyphenol rich foods, fruits, vegetables, and beverages is considered of immense benefit to human health (Vasundev, 2006) as these polyphenols are able to directly scavenge free radicals and inhibit metal-mediated free radical formation (Frei and Higdon, 2003). When compared with endogenous antioxidants, the importance of dietary polyphenols/antioxidants in vivo as oxidant scavengers is considered to be minor due to their lower reduction potentials and bioavailability (Frei and Higdon, 2003). However, these dietary polyphenols have been shown to play greater roles in the prevention of oxidative stress through mechanisms such as: (i) inhibition of redox-sensitive transcription factors [example is nuclear factor-kB (NF-kB)] (ii) down-regulation of pro-oxidant enzymes (example is iNOS and COX-2) and (iii) induction of Phase II enzymes (Frei and Higdon, 2003; Siddiqui et al., 2008; Eleazu et al., 2017).

In recent times, emerging evidence has indicated that apart from the antioxidant activities of polyphenols, polyphenols can also directly or indirectly strengthen the degradation of misfolded and damaged proteins.

Under normal physiological conditions, proteins undergo different conformational changes during their lifetime. Each step is assisted by chaperones and includes de novo folding, assembly and disassembly, transport across membranes, and targeting for degradation (Hajieva, 2017). Therefore, in optimal conditions, long-term health is maintained by protein homeostasis which is a complex network of molecular interactions that balances protein biosynthesis, folding, translocation, assembly, disassembly, and clearance (Dattilo et al., 2015).

The expression of many chaperones is strongly induced under conditions of oxidative stress and heat shock challenges. Therefore, they are considered to be stress proteins or heat shock proteins (Hajieva, 2017) and the ability of a cell to counteract stressful conditions is referred to as cellular stress response or heat shock response (Dattilo et al., 2015).

Production of heat shock proteins, including protein chaperones has been reported to be important for the folding and repair of damaged proteins, leading to cell survival conditions that would have led to apoptosis (Dattilo et al., 2015).

Recently, it has been shown that polyphenols can also directly or indirectly strengthen the degradation of misfolded and damaged proteins as earlier stated. This can be achieved by increasing the activity and efficiency of the cellular protein degradation machinery (Chhangani and Mishra, 2013; Hajieva, 2017). Pharmacologically active polyphenols and their derivatives have been reported to play significant roles in stabilizing the protein degradation machinery at different stages which may be an attractive therapeutic strategy to halt the accumulation of misfolded proteins (Hajieva, 2017). For instance, resveratrol 20 was shown to induce the acute heat shock response by upregulating chaperones like Hsp70 (Putics et al., 2008). Curcumin 18 was reported to demonstrate cytoprotective effects and induce nuclear translocation of HSF1 (Teiten et al., 2009) while also demonstrating anti-inflammatory and antioxidant activities (Hajieva, 2017).

Studies by Scapagnini et al. (2011) showed that curcumin induces hemeoxygenase-1 (HO-1, a heat shock protein) expression and activity in different brain cells via the activation of heterodimers of NF-E2-related factors 2 (Nrf2)/antioxidant responsive element pathway. Furthermore, activation of Nrf2 target genes, and particularly HO-1, in astrocytes and neurons is strongly protective against oxidative damage and cell death (Scapagnini et al., 2011).

In another report, Fetoni et al. (2015) showed that the polyphenol-rosamaric acid attenuated noise-induced hearing loss (which is associated with increase of ROS and lipoperoxidative damage together with the imbalance of 
antioxidant defenses), through activation of the redox-sensitive transcription factor nuclear factor erythroid 2-related factor 2/HO-1 pathway.

\section{PRECLINICAL STUDIES REPORTING ON MANAGEMENT OF BPH WITH DIETARY POLYPHENOLS AND THEIR MECHANISMS OF ACTION}

Currently there are dietary polyphenols that have demonstrated $5 \alpha$-reductase inhibitory properties which makes them promising agents for the management of $\mathrm{BPH}$, but which activities would need to be confirmed using in vivo models of $\mathrm{BPH} /$ clinical studies. For instance, the reports of Hiipakka et al. (2002) working on cell free assays and intact cells, showed that the dietary polyphenols- myricetin, baicalein $(5,6,7$ trihydroxyflavone), fisetin, daidzein, kaempferol, caffeic acid phenethyl ester, octyl and dodecyl gallates inhibited human $5 \alpha$-reductase activities. While in vivo/clinical studies will be needed to confirm these studies, these authors speculated that since these polyphenols were effective on whole cells, they could be capable of modulating the activity of $5 \alpha$-reductase in vivo. Studies conducted by Park et al. (2006) also confirmed the $5 \alpha$-reductase inhibitory activity of kaempferol and caffeic acid phenethyl ester as previously reported by Hiipakka et al. (2002).

On the other hand, there are dietary polyphenols that were reported in preclinical studies to possess the potentials of suppressing BPH. Typical examples are the isoflavonoidsgenistein, biochanin $\mathrm{A}$ and equol and the lignan- enterolactone which were reported to ameliorate $\mathrm{BPH}$ in $\mathrm{BPH}$ tissue homogenates through inhibition of $5 \alpha$-reductase activity (Evans et al., 1995).

ACTICOA powder (contains mostly flavonols), a cocoa polyphenol extract was demonstrated by Bisson et al. (2007) to be useful in ameliorating testosterone propionate-induced prostate hyperplasia in rats.

Again, soybean isoflavones were reported to inhibit $\mathrm{BPH}$ and increase the expressions of nitric oxide and nitric oxide synthase (Yang et al., 2009).

Similarly, quercetin (from onions, red wine, tea, cranberry, and citrus fruits) was reported to suppress $\mathrm{BPH}$ in preclinical studies (Tamler and Mechanick, 2007; Borovskaya et al., 2015) although the mechanism of action is yet to be ascertained.

In another report, flavocoxid, a flavonoid from Scutellaria baicalensis (Chinese skullcap) and Acacia catechu (black catechu), respectively, was reported to demonstrate anti-BPH properties and the mechanism of action was reported to involve decreasing growth factor expression and inhibition of COX-2 and 5lipoxygenase activities in the prostatic tissue of $\mathrm{BPH}$ rats (Altavilla et al., 2012).

Equol (4',7-isoflavandiol), a polyphenol/isoflavonoid molecule derived from soya and intestinal metabolism (Axelson et al., 1984), was reported to suppress BPH in experimental studies. According to the authors, this polyphenol has potent antioxidant and anti-aging properties to decrease prostatic irritation and potentially neoplastic growth. The mechanism of its ameliorating action on BPH was reported as its specific binding to $5 \alpha$-DHT by sequestering $5 \alpha$-DHT from the androgen receptor, thus decreasing androgen hormone actions to improve prostate health by acting as a selective androgen modulator (Edwin, 2014).

Lycopene, a polyphenol commonly found in tomato, was shown to decrease $\mathrm{BPH}$ in animal models of $\mathrm{BPH}$. The mechanism of action was reported to be stimulation of increased expression of the pro-apoptotic protein- caspase-3 and suppression of inflammatory marker- IL-6 (Minutoli et al., 2014).

In another study (Hoon et al., 2010), anthocyanins from black soybean were reported to suppress prostatic hyperplasia in rats induced with $\mathrm{BPH}$. The mechanism of action was reported by the authors to involve suppression of cellular proliferation through induction of apoptosis in the prostatic tissue.

In a more recent study using animal models, we showed the beneficial role of kolaviron, a polyphenol and a biflavonoid complex from Garcinia kola in the management of BPH in $\mathrm{BPH}$ challenged rats (Kalu W. et al., 2016; Kalu W.O. et al., 2016). The mechanism of action was found to involve inhibition of 5 -alpha reductase and oxidative stress in the prostatic tissue. Furthermore, Jinglou and Hongping (2016) in their recent study reported that epigallocatechin-3-gallate had protective effects against testosterone induced $\mathrm{BPH}$ in rats and against $\mathrm{BPH}$ in metabolic syndrome rats. The mechanism of the $\mathrm{BPH}$ protective action of this polyphenol on the experimental $\mathrm{BPH}$ induced rats was reported by the authors to involve repair of the antioxidant defense mechanisms (superoxide dismutase and glutathione peroxidase) in the prostate with concomitant diminution of prostatic levels of malonaldehyde; diminution of the prostatic levels of the inflammatory markers- interleukin (IL)-I $\beta$, IL-I6, tumor necrosis factor- $\alpha$ (TNF- $\alpha)$; inhibition of IGF-I and IGFII as well as upregulation of peroxisome proliferator-activated receptors (PRAR) $-\alpha$ and PPAR- $\gamma$ that have been shown to contribute to apoptosis. Another very recent study (Ren et al., 2016) also reported the treatment effects of flaxseed-derived secoisolariciresinol diglycoside (a lignan extracted from flaxseed) and its metabolite enterolactone on BPH. The mechanistic basis for its anti-BPH activity was reported by the authors to involve stimulation of increased expression of G-protein-coupled estrogen receptor 1 (GPER) that has been reported to decrease cell proliferation by activating apoptosis in some cells (Chimento et al., 2013).

\section{CLINICAL STUDIES/MANAGEMENT OF BPH WITH DIETARY POLYPHENOLS}

Until now, the concept of management of BPH using dietary polyphenols has been under debate due to a number of clinical studies that gave contrary results as well as the adverse effects some of these polyphenols could pose following long term exposure.

For instance, in the review by Curtis et al. (2008), they listed some phytotherapies that are used in BPH management such as 
quercetin and others but showed the lack of clinical effects of some of these phytotherapies although clinical study conducted on BPH management with quercetin (Shoskes et al., 1999) and reviewed by Curtis et al. (2008), did not deny the anti-BPH effect of quercetin. Moreover, the double-blind randomized clinical trial conducted by Ghorbanibirgani (2012) provided evidence of the efficacy of quercetin in the treatment of $\mathrm{BPH}$.

Again, clinical studies conducted on $\mathrm{BPH}$ management with resveratrol as reported by Kjaer et al. (2015) did not support the management of $\mathrm{BPH}$ with this polyphenol.

However, some other clinical studies carried out on $\mathrm{BPH}$ management with some dietary polyphenols provided evidence of their usefulness in the management of BPH.

For example, in a study carried out on the effects of a low oral dose of equol supplement (6 $\mathrm{mg}$, twice a day with meals) for 4 weeks in a total of 18 men (49-60 years old) with moderate or severe BPH (Lephart, 2013), it was shown that a low dose of equol positively improved moderate to severe $\mathrm{BPH}$ symptoms according to the IPSS indices. In moderately symptomatic men, 5 out of 7 of the IPSS parameters significantly improved by 4 weeks of equol treatment while in severely symptomatic men, all 7 of the IPSS parameters significantly improved with
4 weeks of equol treatment. In addition, their study also showed that $5 \alpha$-DHT levels declined by $21 \%$ in severely symptomatic men.

In a randomized, double-blind, placebo-controlled trial that investigated the effects of lycopene supplementation in elderly men diagnosed with BPH (Schwarz et al., 2008), it was reported that lycopene inhibited $\mathrm{BPH}$ progression and ameliorated the $\mathrm{BPH}$ symptoms in the patients at a dose of $15 \mathrm{mg}$ /day for 6 months and which finding was supported by later experimental studies conducted by Minutoli et al. (2014) on the management of $\mathrm{BPH}$ with lycopene. Furthermore, the authors (Schwarz et al., 2008) also reported the lycopene supplements to be safe and well tolerated.

Similarly, in a 4 months randomized, double-blind, placebocontrolled clinical trial carried out in 87 subjects with $\mathrm{BPH}$ receiving treatment dosages of 0 (placebo), 300, or $600 \mathrm{mg} /$ day of the flaxseed lignan extract (secoisolariciresinol diglucoside (SDG) (Zhang et al., 2008), the authors showed that for the 0, 300, and $600 \mathrm{mg} /$ day SDG groups, respectively, the International Prostate Symptom Score decreased by $-3.67 \pm 1.56,-7.33 \pm 1.18$, and $-6.88 \pm 1.43$ (mean $\pm \mathrm{SE}, P=0.100,<0.001$, and $<0.001$ compared to baseline), while the Quality of Life score improved

TABLE 1 | Dietary polyphenols identified with $5 \alpha$-reductase inhibitory actions.

\begin{tabular}{|c|c|c|}
\hline Polyphenols & Source & Activity \\
\hline Myricetin & Red wine & $5 \alpha$-reductase inhibition (Hiipakka et al., 2002) \\
\hline Baicalein & Scutellaria baicalensis and Scutellaria lateriflora & 5 $\alpha$-reductase inhibition (Hiipakka et al., 2002) \\
\hline Fisetin & Strawberries, apples, grapes & $5 \alpha$-reductase inhibition (Hiipakka et al., 2002) \\
\hline Daidzein & Soybeans & $5 \alpha$-reductase inhibition (Hiipakka et al., 2002) \\
\hline Kaempferol & Apples, broccoli, onions, tomatoes & 5 $\alpha$-reductase inhibition (Hiipakka et al., 2002; Park et al., 2006) \\
\hline Caffeic acid-phenethyl ester & Propolis & 5 $\alpha$-reductase inhibition (Hiipakka et al., 2002; Park et al., 2006) \\
\hline Octyl gallate & Octanol and gallic acid (produced from plant tannins) & $5 \alpha$-reductase inhibition (Hiipakka et al., 2002) \\
\hline Dodecyl gallates & Gallic acid (from plan tannins) & $5 \alpha$-reductase inhibition (Hiipakka et al., 2002) \\
\hline
\end{tabular}

TABLE 2 | Dietary polyphenols identified with BPH suppressing properties.

\begin{tabular}{|c|c|c|}
\hline Polyphenol & Source & Mechanisms of action \\
\hline Epigallocatechin-gallate & Green tea & $\begin{array}{l}\text { Suppression of oxidative stress, diminution of inflammatory markers (IL-I } 1 \beta \text {, IL-I6, } \\
\text { and TNF- } \alpha \text {; inhibition of IGF-I and IGF-II and upregulation of PPAR- } \alpha \text { and } \\
\text { PPAR- } \gamma \text { (Jinglou and Hongping, 2016) }\end{array}$ \\
\hline Lignan & Flaxseeds, sesame seeds & $5 \alpha$-reductase inhibition (Evans et al., 1995) \\
\hline Genistein & Fava beans, soybeans & 5 $\alpha$-reductase inhibition (Evans et al., 1995) \\
\hline Biochanin A & Soy, Peanuts & 5 $\alpha$-reductase inhibition (Evans et al., 1995) \\
\hline Enterolactone & Flaxseed and sesame sees & $5 \alpha$-reductase inhibition (Evans et al., 1995) \\
\hline Flavocoxid & Scutellaria baicalensis and Acacia catechu & $\begin{array}{l}\text { Inhibition of growth factor expression and suppression of inflammation through } \\
\text { inhibition of cyclooxygenase-2 and 5-lipoxygenase activities (Altavilla et al., } \\
\text { 2012) }\end{array}$ \\
\hline Equol & Soya & $\begin{array}{l}\text { Binding to } 5 \alpha-\mathrm{DHT} \text { by sequestering } 5 \alpha \text {-DHT from the androgen receptor (Evans } \\
\text { et al., 1995; Edwin, 2014) }\end{array}$ \\
\hline Anthocyanin & Soya & $\begin{array}{l}\text { Suppression of cellular proliferation through induction of apoptosis (Hoon et al., } \\
\text { 2010). }\end{array}$ \\
\hline Lycopene & Tomato & Upregulation of caspase-3 and suppression of IL-6 (Minutoli et al., 2014) \\
\hline Kolaviron & Garcinia kola & $\begin{array}{l}\text { Inhibition of } 5 \alpha \text {-reductase and suppression of oxidative stress in the prostatic } \\
\text { tissue (Kalu W. et al., 2016) }\end{array}$ \\
\hline Secoisolariciresinol diglucoside & Flaxseed & $\begin{array}{l}\text { Stimulation of increased expression of G-protein-coupled estrogen receptor } 1 \\
\text { (Ren et al., 2016) }\end{array}$ \\
\hline
\end{tabular}




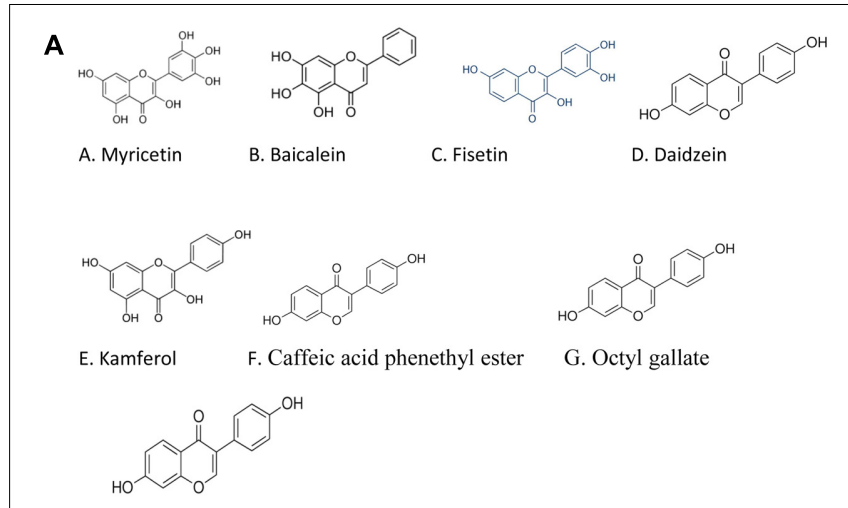

H. Dodecyl gallates

B

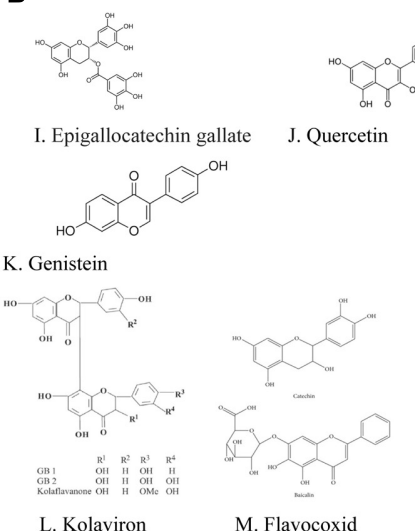

L. Kolaviron M. Flavocoxid
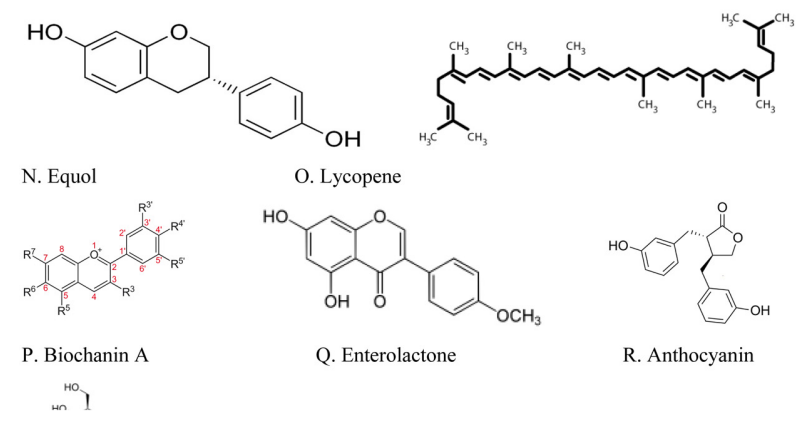

Q. Enterolactone

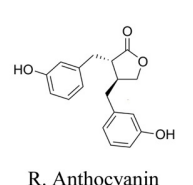

FIGURE 1 | (A) Structures of the polyphenols with $5 \alpha$-reductase inhibitory actions. (B) Structures of polyphenols with BPH suppressing actions in preclinical studies. by $-0.71 \pm 0.23,-1.48 \pm 0.24$, and $-1.75 \pm 0.25$ (mean $\pm \mathrm{SE}$, $P=0.163$ and 0.012 compared to placebo. In addition, the authors suggested the therapeutic efficacy of this polyphenol to be comparable to that of the commonly used intervention agents of alpha1A-adrenoceptor blockers and $5 \alpha$-reductase inhibitors. The finding by these authors with respect to $\mathrm{BPH}$ management using this polyphenol was further affirmed by the later experimental study conducted by Ren et al. (2016).

Similarly, the double-blind randomized clinical trial conducted by Ghorbanibirgani (2012) provided evidence of the efficacy of quercetin in the treatment of BPH as earlier stated.
Other clinical studies carried out supported the use of phytotherapies from different plants such as Eviprostat (Matsumoto et al., 2010), Pygeum africanum extract (Chatelain et al., 1999), Stinging nettle root extract (Bazotonuno) (Schneider and Rübben, 2004), PR-2000 (Tribulus terrestris) (Sahu and Kumar, 2001), and others in the management of BPH but which are beyond the scope of this review as the actual polyphenols in these phytotherapies were not indicated in these studies.

\section{ADVERSE EFFECTS ASSOCIATED WITH UNCONTROLLED AND LONG-LASTING SUPPLEMENTATION WITH DIETARY POLYPHENOLS}

While the contribution of some dietary polyphenols in the management of $\mathrm{BPH}$ has been indicated in this review as supported by clinical findings, it must also be emphasized that non-regulated and long-lasting supplementation with some dietary polyphenols could lead to potential harmful effects due to possible interactions with cytochrome P450 (CYP) enzymes (Mancuso, 2015).

Amongst the CYP enzymes which are responsible for the metabolism of a wide array of endogenous substances, (examplesteroids, hormones, lipids, and bile acids), xenobiotics (exampledrugs and pollutants from the environment), and dietary products and/dietary polyphenols, CYP $3 \mathrm{~A} 4$ has been shown to be the major enzyme that is involved in the metabolism of drugs and xenobiotics in the liver and gut (Loai and Zohar, 2015). It has also been shown to be expressed in the prostate, breast, gut, colon, small intestine, and the brain (Ferguson and Tyndale, 2011; Loai and Zohar, 2015).

In recent times, studies have also suggested possible interactions between dietary polyphenols and CYP 3A4, which could lead to some adverse effects.

For instance, Mancuso and Barone (2009) reported that curcumin and its derivatives inhibit the activity of CYP3A4 and other drug-metabolizing enzymes such as: glutathione$S$-transferase and UDP-glucuronosyltransferase. These authors reported that inhibition by curcumin, alone or in combination with piperine, of CYP3A4 could be harmful, especially during prolonged usage.

Kimura et al. (2010) in their study, showed the inhibitory effects of polyphenols on human CYP3A4 and CYP2C9 activity in vitro which inhibitory actions were reported by the authors to involve the formation of a covalent bond between the polyphenol and the CYP3A4 molecule, leading to the inactivation of the enzyme, or reversible binding that causes reversible inhibition. Similarly, the-flavonols kaempferol, quercetin, and galangin were reported to inhibit CYP3A4-mediated metabolism of xenobiotics in vitro (Shimada et al., 2010; Loai and Zohar, 2015). Furthermore, inhibitory effects of catechins on CYP3A4 were reported in some studies (Kimura et al., 2010; Yang and Pan, 2012), although no specific mechanisms of action were reported in these studies. 
One thing most of these studies reporting on the interaction of polyphenols with CYP enzymes have shown is the need for controlled/regulated use of polyphenols for therapeutic purposes.

Table 1 shows the dietary polyphenols identified in this review with $5 \alpha$-reductase inhibitory activities but which activities would need to be confirmed using in vivo/clinical studies; Table 2 summarizes the mechanisms through which the dietary polyphenols identified in the preclinical studies with $\mathrm{BPH}$ suppressing properties exert their biological effects; the structures of the polyphenols with $5 \alpha$-reductase inhibitory properties are shown in Figure 1A while the structures of the polyphenols identified in the preclinical studies with $\mathrm{BPH}$ suppressing properties are shown in Figure 1B.

\section{REFERENCES}

Abd, E. M. M., Marks, J., Kuhnle, G., Moore, K., Debnam, E., Srai, S. K., et al. (2006). Absorption, tissue distribution and excretion of pelargonidin and its metabolites following oral administration to rats. Br. J. Nutr. 95, 51-58. doi: 10.1079/BJN20051596

Alberto, B., Umberto, C., Nazareno, S., Andrea, G., Andrea, S., Marco, B., et al. (2009). Benign prostatic hyperplasia and its aetiologies. Eur. Urol. Suppl. 8, 865-871. doi: 10.1016/j.eursup.2009.11.002

Aleksandra, R., Iwona, R., Tomasz, M., Marcin, S., Barbara, D., Anna, L., et al. (2015). Metabolic syndrome and benign prostatic hyperplasia: association or coincidence? Diabetol. Metab. Syndr. 7:94. doi: 10.1186/s13098-015-0089-1

Aline, B., Alain, R., Myriam, D., Jean, A., Marian, D., Mohamed, B., et al. (2005). Activation of Caspases-3, -6 , and -9 during finasteride treatment of benign prostatic hyperplasia. J. Clin. Endocrinol. Metab. 90, 17-25. doi: 10.1210/jc. 2004-0712

Altavilla, D., Minutoli, L., Polito, F., Irrera, N., Arena, S., Magno, C., et al. (2012). Effects of flavocoxid, a dual inhibitor of COX and 5-lipoxygenase enzymes, on benign prostatic hyperplasia. Br. J. Pharmacol. 167, 95-108. doi: 10.1111/j.14765381.2012.01969.x

Aruna, R., Geetha, A., and Suguna, P. (2014). Rutin modulates ASC expression in NLRP3 inflammasome: a study in alcohol and cerulein-induced rat model of pancreatitis. Mol. Cell. Biochem. 396, 269-280. doi: 10.1007/s11010-014-2162-8

Axelson, M., Sjövall, J., Gustafsson, B. E., and Setchell, K. D. (1984). Soya-a dietary source of the non-steroidal oestrogen equol in man and animals. J. Endocrinol. 102, 49-56. doi: 10.1677/joe.0.1020049

Barkin, J. (2011). Benign prostatic hyperplasia and lower urinary tract symptoms: evidence and approaches for best case management. Can. J. Urol. 18, 14-19.

Bisson, J. F., Hidalgo, S., Rozan, P., and Messaoudi, M. (2007). Therapeutic effect of ACTICOA powder, a cocoa polyphenolic extract, on experimentally induced prostate hyperplasia in Wistar-Unilever rats. J. Med. Food 10, 622-627. doi: 10.1089/jmf.2006.243

Borovskaya, T. G., Krivova, N. A., Zaeva, O. B., Fomina, T. I., Kamalova, S. I., and Poluektova, M. E. (2015). Dihydroquercetin effects on the morphology and antioxidant/prooxidant balance of the prostate in rats with sulpiride-induced benign hyperplasia. Bull. Exp. Biol. Med. 158, 513-516. doi: 10.1007/s10517015-2797-9

Cassidy, A., Hansley, B., and Lamuela-Raventos, R. M. (2000). Isoflavones, lignans and stilbenes-origins, metabolism and potential importance to human health. J. Sci. Food Agric. 80, 1044-1062. doi: 10.1002/(SICI)1097-0010(20000515)80: 7<1044::AID-JSFA586>3.0.CO;2-N

Chatelain, C., Autet, W., and Brackman, F. (1999). Comparison of once and twice daily dosage forms of Pygeum africanum extract in patients with benign prostatic hyperplasia: a randomized, double-blind study, with long-term open label extension. Urology 54, 473-478. doi: 10.1016/S0090-4295(99)00147-8

Chhangani, D., and Mishra, A. (2013). Protein quality control system in neurodegeneration: a healing company hard to beat but failure is fatal. Mol. Neurobiol. 48, 141-156. doi: 10.1007/s12035-013-8411-0

Chimento, A., Casaburi, I., Bartucci, M., Patrizii, M., Dattilo, R., Avena, P., et al. (2013). Selective GPER activation decreases proliferation and

\section{CONCLUSION}

While this review does not state emphatically that dietary polyphenols could replace the need for the existing therapies in the management of $\mathrm{BPH}$, it suggests the promise some dietary polyphenols hold in $\mathrm{BPH}$ management which could be explored by researchers working in this field.

\section{AUTHOR CONTRIBUTIONS}

$\mathrm{CE}, \mathrm{KE}$, and WK reviewed the cited literature and wrote the manuscript. All authors read and approved the final manuscript.

activates apoptosis in tumor Leydig cells. Cell Death Dis. 4:e747. doi: 10.1038/cddis.2013.275

Corona, G., Vignozzi, L., Rastrelli, G., Lotti, F., Cipriani, S., and Maggi, M. (2014). Benign prostatic hyperplasia: a new metabolic disease of the aging male and its correlation with sexual dysfunctions. Int. J. Endocrinol. 2014:329456. doi: $10.1155 / 2014 / 329456$

Curtis, N. J., Daniel, S., Roehrborn, C. G., and Mark, M. (2008). Nutraceuticals in prostate disease: the urologist's role. Rev. Urol. 10, 192-206.

Dattilo, S., Mancuso, C., Koverech, G., Mauro, D. P., Ontario, M. L., Petralia, C. C., et al. (2015). Heat shock proteins and hormesis in the diagnosis and treatment of neurodegenerative diseases. Immun. Ageing 12:20. doi: 10.1186/s12979-0150046-8

Di Silverio, F., Gentile, V., and De-Matteis, A. (2003). Distribution of inflammation, pre-malignant lesions, incidental carcinoma in histologically confirmed benign prostatic hyperplasia: a retrospective analysis. Eur. Urol. 43, 164-175. doi: 10.1016/S0302-2838(02)00548-1

Donnelly, L. E., Newton, R., Kennedy, G. E., Fenwick, P. S., Leung, R. H., Ito, K., et al. (2004). Anti-inflammatory effects of resveratrol in lung epithelial cells: molecular mechanisms. Am. J. Physiol. Lung Cell. Mol. Physiol. 287, L774-L783. doi: 10.1152/ajplung.00110.2004

Edwin, D. L. (2014). Anti-oxidant and anti-aging properties of equol in prostate health. Open J. Endocr. Metab. Dis. 4, 1-12. doi: 10.4236/ojemd.2014.41001

Eleazu, C., Obianuju, N., Eleazu, K., and Kalu, W. (2017). The role of dietary polyphenols in the management of erectile dysfunction-mechanisms of action. Biomed. Pharmacother. 88, 644-652. doi: 10.1016/j.biopha.2017.01.125

Eleazu, C. O. (2016). Characterization of the natural products in cocoyam (Colocasia esculenta) using GC-MS. Pharm. Biol. 54, 2880-2885. doi: 10.1080/ 13880209.2016.1190383

Eleazu, C. O., and Eleazu, K. C. (2015). Nutrient composition: antioxidant capacity and natural products in livingstone potato (Plectranthus esculentus). J. Food Process. Preserv. 39, 3050-3058. doi: 10.1111/jfpp.12570

Eleazu, C. O., Iroaganachi, M., Okafor, P. N., Ijeh, I. I., and Eleazu, K. C. (2013a). Ameliorative potentials of ginger ( $Z$. officinale Roscoe) on relative organ weights in streptozotocin induced diabetic rats. Int. J. Biomed. Sci. 9, 82-90.

Eleazu, C. O., Iroaganachi, M. A., Eleazu, K. C., and Okoronkwo, J. O. (2013b). Determination of the physico-chemical composition, microbial quality and free radical scavenging activities of some commercially sold honey samples in Aba, Nigeria: 'the effect of varying colours'. Int. J. Biomed. Res. 4, 32-41.

Evans, B. A., Griffiths, K., and Morton, M. S. (1995). Inhibition of 5 alphareductase in genital skin fibroblasts and prostate tissue by dietary lignans and isoflavonoids. J. Endocrinol. 147, 295-302. doi: 10.1677/joe.0.1470295

Ferguson, C. S., and Tyndale, R. F. (2011). Cytochrome P450 enzymes in the brain: emerging evidence of biological significance. Trends Pharmacol. Sci. 32, 708-714. doi: 10.1016/j.tips.2011.08.005

Fetoni, A. R., Paciello, F., Rolesi, R., Eramo, S. L., Mancuso, C., Troiani, D., et al. (2015). Rosmarinic acidup-regulates the noise-activated Nrf2/HO-1 pathway and protects against noise-induced injury in rat cochlea. Free Radic. Biol. Med. 85, 269-281. doi: 10.1016/j.freeradbiomed.2015.04.021 
Frei, B., and Higdon, J. V. (2003). Antioxidant activity of tea polyphenols in vivo: evidence from animal studies. J. Nutr. 133, 3275S-3284S.

Ghorbanibirgani, A. (2012). Efficacy of quercetin in treatment of benign prostatic hyperplasia in a double-blind randomized clinical trial in Iran-2011. Contraception 85, 321. doi: 10.1016/j.contraception.2011.11.038

Giacomo, N., Antonio, G., Rafael, B. B., Vincenzo, F., Remigio, V. N., and Walter, A. (2006). Inflammation, apoptosis, and BPH: what is the evidence? Eur. Urol. Suppl. 5, 401-409. doi: 10.1016/j.eursup.2006.02.003

Hajieva, P. (2017). The effect of polyphenols on protein degradation pathways: implications for neuroprotection. Molecules 22:159. doi: 10.3390/molecules22010159

Hamid, A. R., Umbas, R., and Mochtar, C. A. (2011). Recent role of inflammation in prostate diseases: chemoprevention development opportunity. Acta Med. Indones. 43, 59-65.

Hammarsten, J., and Högstedt, B. (2001). Hyperinsulinaemia as a risk factor for developing benign prostatic hyperplasia. Eur. Urol. 39, 151-158. doi: 10.1159/ 000052430

Han, X., Shen, T., and Lou, H. (2007). Dietary polyphenols and their biological significance. Int. J. Mol. Sci. 8, 950-988. doi: 10.3390/i8090950

Hatcher, H., Planalp, R., Cho, J., Torti, F. M., and Torti, S. V. (2008). Curcumin: from ancient medicine to current clinical trials. Cell. Mol. Life Sci. 65, 1631-1652. doi: 10.1007/s00018-008-7452-4

Henning, S. M., Aronson, W. N., Conde, F., Lee, F., Seeram, N. H., Lee, N. P., et al. (2006). Tea polyphenols and theaflavins are present in prostate tissue of humans and mice after green and black tea consumption. J. Nutr. 136, 1839-1843.

Hiipakka, R. A., Zhang, H. Z., Dai, W., Dai, Q., and Liao, S. (2002). Structure-activity relationships for inhibition of human 5alpha-reductases by polyphenols. Biochem. Pharmacol. 63, 1165-1176. doi: 10.1016/S0006-2952(02) 00848-1

Ho, C. K. M., and Habib, F. K. (2011). Estrogen and androgen signaling in the pathogenesis of BPH. Nat. Rev. Urol. 8, 29-41. doi: 10.1038/nrurol.2010.207

Hollman, P. C., and Arts, I. C. (2000). Flavonols, flavones and flavanols-nature, occurrence and dietary burden. J. Sci. Food Agric. 80, 1081-1093. doi: 10.1002/ (SICI) 1097-0010(20000515)80:7<1081::AID-JSFA566>3.0.CO;2-G

Hoon, J., U-Syn, H., Su-Jin, K., Byung-Il, Y., Dong-Seok, H., Seung-Mo, Y., et al. (2010). Anthocyanin extracted from black soybean reduces prostate weight and promotes apoptosis in the prostatic hyperplasia-induced rat model. J. Agric. Food Chem. 58, 12686-12691. doi: 10.1021/jf102688g

Huynh, H., Seyam, R. M., and Brock, G. B. (1998). Reduction of ventral prostate weight by finasteride is associated with suppression of insulin-like growth factor I (IGF-I), IGF-I receptor and an increase in IGF binding protein 3. Cancer Res. $58,215-218$.

Ichikawa, D., Matsui, A., Imai, M., Sonoda, Y., and Kasahara, T. (2004). Effect of various catechins on the IL-12p40 production by murine peritoneal macrophages and a macrophage cell line, J774.1. Biol. Pharm. Bull. 27, 1353-1358. doi: 10.1248/bpb.27.1353

In, S. S., Mee, Y. L., Hye, K. H., Chang, S. S., and Hyeun-Kyoo, S. (2012). Inhibitory effect of Yukmijihwang-tang, a traditional herbal formula against testosteroneinduced benign prostatic hyperplasia in rats. BMC Complement. Alternat. Med. 12:48.

Jeyaraj, D. A., Uduyakumar, T. S., Rajalakshmi, M., Pal, P. C., and Sharma, R. S. (2000). Effects of long term administration of androgens and estrogen on Rhesus monkey prostate: possible induction of benign prostatic hyperplasia. J. Androl. 21, 833-841.

Jinglou, C., and Hongping, S. (2016). Protective potential of epigallocatechin3 -gallate against benign prostatic hyperplasia in metabolic syndrome rats. Environ. Toxicol. Pharmacol. 45, 315-320. doi: 10.1016/j.etap.2016.06.015

Kalu, W., Okafor, P., Ijeh, I., and Eleazu, C. (2016). Effect of fractions of kolaviron on some indices of benign prostatic hyperplasia in rats: identification of the constituents of the bioactive fraction using GC-MS. RSC Adv. 6, 94352-94360. doi: 10.1039/C6RA18266F

Kalu, W. O., Okafor, P. N., Ijeh, I. I., and Eleazu, C. (2016). Effect of kolaviron, a biflavanoid complex from Garcinia kola on some biochemical parameters in experimentally induced benign prostatic hyperplasic rats. Biomed. Pharmacother. 83, 1436-1443. doi: 10.1016/j.biopha.2016.08.064

Kessler, O. J., Keisari, Y., Servadio, C., and Abramovici, A. (1998). Role of chronic inflammation in the promotion of prostatic hyperplasia in rats. J. Urol. 159, 1049-1053. doi: 10.1016/S0022-5347(01)63834-5
Khan, N., and Mukhtar, H. (2007). Tea polyphenols for health promotion. Life Sci. 81, 519-533. doi: 10.1016/j.lfs.2007.06.011

Kimura, Y., Ito, H., Ohnishi, R., and Hatano, T. (2010). Inhibitory effects of polyphenols on human cytochrome P450 3A4 and 2C9 activity. Food Chem. Toxicol. 48, 429-435. doi: 10.1016/j.fct.2009.10.041

Kirschenbaum, A., Klausner, A. P., Lee, R., Unger, P., Yao, S., and Liu, X. H. (2000). Expression of cyclooxygenase-1 and cyclooxygenase- 2 in the human prostate. Urology 56, 671-676. doi: 10.1016/S0090-4295(00)00674-9

Kjaer, T. N., Ornstrup, M. J., Poulsen, M. M., Jørgensen, J. O., Hougaard, D. M., Cohen, A. S., et al. (2015). Resveratrol reduces the levels of circulating androgen precursors but has no effect on, testosterone, dihydrotestosterone, PSA levels or prostate volume. A 4-month randomised trial in middle-aged men. Prostate 75 , 1255-1263. doi: 10.1002/pros.23006

Knaup, B., Kahle, K., Erk, T., Valotis, A., Scheppach, W., Schreier, P., et al. (2007). Human intestinal hydrolysis of phenol glycosides - a study with quercetin and p-nitrophenol glycosides using ileostomy fluid. Mol. Nutr. Food Res. 51, 1423-1429. doi: 10.1002/mnfr.200700036

Kramer, G., Mitteregger, D., and Marberger, M. (2007). Is benign prostatic hyperplasia (BPH) an immune inflammatory disease? Eur. Urol. 51, 1202-1216.

Kroeger, N., Belldegrun, A. S., and Pantuck, A. J. (2013). Pomegranate extracts in the management of men's urologic health: scientific rationale and preclinical and clinical data. Evid. Based Complement. Alternat. Med. 2013:870454. doi: 10.1155/2013/701434

Kyprianou, N. (2003). Doxazosin and terazosin suppress prostate growth by inducing apoptosis: clinical significance. J. Urol. 169, 1520-1525. doi: 10.1097/ 01.ju.0000033280.29453.72

Kyprianou, N., Tu, H., and Jacobs, S. C. (1996). Apoptotic versus proliferative activities in human benign prostatic hyperplasia. Hum. Pathol. 27, 668-675. doi: 10.1016/S0046-8177(96)90396-2

Lee, K. L., and Peehl, D. M. (2004). Molecular and cellular pathogenesis of benign prostatic hyperplasia. J. Urol. 172, 1784-1791. doi: 10.1097/01.ju.0000133655. 71782.14

Lephart, E. D. (2013). Severe and moderate BPH symptoms in mid-aged men improved with isoflavonoid-equol treatment: pilot intervention study. Open J. Urol. 3, 21-27. doi: 10.4236/oju.2013.31004

Liu, L., Li, Q., Han, P., Li, X., Zeng, H., Zhu, Y., et al. (2009). Evaluation of interleukin-8 in expressed prostatic secretion as a reliable biomarker of inflammation in benign prostatic hyperplasia. Urology 74, 340-344. doi: 10.1016/j.urology.2009.02.064

Loai, B., and Zohar, K. (2015). Interactions between CYP3A4 and dietary polyphenols. Oxid. Med. Cell. Longev. 2015:854015. doi: 10.1155/2015/ 854015

Ly, C., Yockell-Lelièvre, J., Ferraro, M. Z., Arnason, J. T., Ferrier, J., and Gruslin, A. (2015). The effects of dietary polyphenols on reproductive health and early development. Hum. Reprod. Update 21, 228-248. doi: 10.1093/ humupd/dmu058

Manach, C., and Donovan, J. L. (2004). Pharmacokinetics and metabolism of dietary flavonoids in humans. Free Radic. Res. 38, 771-785. doi: 10.1080/ 10715760410001727858

Mancuso, C. (2015). Key factors which concur to the correct therapeutic evaluation of herbal products in free radical-induced diseases. Front. Pharmacol. 6:86. doi: 10.3389/fphar.2015.00086

Mancuso, C., and Barone, E. (2009). Curcumin in clinical practice: myth or reality? Trends Pharmacol. Sci. 30, 333-334. doi: 10.1016/j.tips.2009.04.004

Matsumoto, S., Hanai, T., Matsui, T., Oka, M., Tanaka, M., and Uemura, H. (2010). Eviprostat suppresses urinary oxidative stress in a rabbit model of partial bladder outlet obstruction and in patients with benign prostatic hyperplasia. Phytother. Res. 24, 301-303. doi: 10.1002/ptr.2909

McVary, K. T. (2006). BPH: epidemiology and comorbidities. Am. J. Manag. Care $12, \mathrm{~S} 122-\mathrm{S} 128$.

Minciullo, P. L., Inferrera, A., Navarra, M., Calapai, G., Magno, C., and Gangemi, S. (2015). Oxidative stress in benign prostatic hyperplasia: a systematic review. Urol. Int. 94, 249-254. doi: 10.1159/000366210

Minutoli, L., Altavilla, D., Marini, H., Rinaldi, M., Irrera, N., Pizzino, G., et al. (2014). Inhibitors of apoptosis proteins in experimental benign prostatic hyperplasia: effects of Serenoa repens, selenium and lycopene. J. Biomed. Sci. 21:19. doi: 10.1186/1423-0127-21-19 
Mishra, V. C., Allen, D. J., Nicolaou, C., Sharif, H., Hudd, C., Karim, O. M., et al. (2007). Does intraprostatic inflammation have a role in the pathogenesis and progression of benign prostatic hyperplasia? BJU Int. 100, 327-331.

Mojzer, B. E., Hrnèiè, M. K., Škerget, M., Knez, K., and Bren, U. (2016). Polyphenols: extraction methods, antioxidative action, bioavailability and anticarcinogenic effects. Molecules 21:901. doi: 10.3390/molecules21070901

Nemeth, K., Plumb, G. W., and Berrin, J. G. (2003). Deglycosylation by small intestinal epithelial cell-glucosidases is a critical step in the absorption and metabolism of dietary flavonoid glycosides in humans. Eur. J. Nutr. 42, 29-42. doi: 10.1007/s00394-003-0397-3

Neuhouser, M. L., Schenk, J., Song, Y. J., Catherine, M. T., Phyllis, J. G., Michael, P., et al. (2008). Insulin-like growth factor-I, insulin-like growth factor binding protein-3 and risk of benign prostate hyperplasia in the prostate cancer prevention trial. Prostate 68, 1477-1486. doi: 10.1002/pros.20819

Nickel, J. C., Roehrborn, C. G., O’Leary, M. P., Bostwick, D. G., Somerville, M. C., and Rittmaster, R. S. (2008). The relationship between prostate inflammation and lower urinary tract symptoms: examination of baseline data from the REDUCE trial. Eur. Urol. 54, 1379-1384. doi: 10.1016/j.eururo.2007. 11.026

Pandey, K. B., and Rizvi, S. I. (2009). Plant polyphenols as dietary antioxidants in human health and disease. Oxid. Med. Cell. Longev. 2, 270-278. doi: 10.4161/ oxim.2.5.9498

Park, J. S., Yeom, M. H., Park, W. S., Joo, K. M., Rho, H. S., Kim, D. H., et al. (2006). Enzymatic hydrolysis of green tea seed extract and its activity on 5alphareductase inhibition. Biosci. Biotechnol. Biochem. 70, 387-394. doi: 10.1271/bbb. 70.387

Prasad, K. (2012). Resveratrol, wine, and atherosclerosis. Int. J. Angiol. 21, 7-18. doi: 10.1055/s-0032-1306417

Putics, A., Végh, E. M., Csermely, P., and Soti, C. (2008). Resveratrol induces the heat-shock response and protects human cells from severe heat stress. Antioxid. Redox Signal. 10, 65-76. doi: 10.1089/ars.2007.1866

Rajasekaran, M., Hellstrom, W. J., and Sikka, S. C. (2001). Nitric oxide induces oxidative stress and mediates cytotoxicity to human cavernosal cells in culture. J. Androl. 22, 34-39.

Ren, G. Y., Chen, C. Y., Chen, W. G., Huang, Y., Qin, L. Q., and Chen, L. H. (2016). The treatment effects of flaxseed-derived secoisolariciresinol diglycoside and its metabolite enterolactone on benign prostatic hyperplasia involve the $\mathrm{G}$ protein-coupled estrogen receptor 1. Appl. Physiol. Nutr. Metab. 41, 1303-1310. doi: 10.1139/apnm-2016-0332

Rodriguez-Berriguete, G., Fraile, B., De-Bethencourt, F. R., Prieto-Folgado, A., Bartolome, N., Nunez, C., et al. (2010). Role of IAPs in prostate cancer progression: immunohistochemical study in normal and pathological (benign hyperplastic, prostatic intraepithelial neoplasia and cancer) human prostate. BMC Cancer 10:18. doi: 10.1186/1471-2407-10-18

Roehrborn, C. G., and McConnell, J. (2002). "Etiology, pathophysiology, epidemiology and natural history of benign prostatic hyperplasia," in Campbell's Urology, 8th Edn, eds P. Walsh, A. Retik, E. Vaughan, and A. Wein (Philadelphia, PA: Saunders), 1297-1336.

Saez, C., Gonzalez-Baena, A. C., and Japon, M. A. (1998). Regressive changes in finasteride-treated human hyperplastic prostates correlate with an upregulation of TGF-b receptor expression. Prostate 37, 84-90. doi: 10.1002/(SICI)10970045(19981001)37:2<84::AID-PROS4>3.0.CO;2-L

Sahu, M., and Kumar, V. (2001). Efficacy and safety of a herbal preparation PR2000 in the treatment of symptomatic benign prostatic hyperplasia. JAMA 4, $43-45$.

Scalbert, A., Johnson, I. T., and Saltmarsh, M. (2005). Polyphenols: antioxidants and beyond. Am. J. Clin. Nutr. 81, 215S-217S.

Scapagnini, G., Sonya, V., Nader, A. G., Calogero, C., Zella, D., and Fabio, G. (2011). Modulation of Nrf2/ARE pathway by food polyphenols: a nutritional neuroprotective strategy for cognitive and neurodegenerative disorders. Mol. Neurobiol. 44, 192-201. doi: 10.1007/s12035-011-8181-5

Schneider, T., and Rübben, H. (2004). Stinging nettle root extract (Bazotonuno) in long term treatment of benign prostatic syndrome (BPS). Results of a randomized, double-blind, placebo controlled multicenter study after 12 months. Urologe A 43, 302-306.

Schwarz, S., Obermüller-Jevic, U. C., Hellmis, E., Koch, W., Jacobi, G., and Biesalski, H. K. (2008). Lycopene inhibits disease progression in patients with benign prostate hyperplasia. J. Nutr. 138, 49-53.
Sciarra, A., Mariotti, G., Salciccia, S., Gomez, A. A., Monti, S., and Toscano, V. (2008). Prostate growth and inflammation. J. Steroid Biochem. Mol. Biol. 108, 254-260. doi: 10.1016/j.jsbmb.2007.09.013

Shariat, S. F., Ashfaq, R., Roehrborn, C. G., Slawin, K. M., and Lotan, Y. (2005). Expression of survivin and apoptotic biomarkers in benign prostatic hyperplasia. J. Urol. 174, 2046-2050. doi: 10.1097/01.ju.0000176459.79180.d1

Shimada, T., Tanaka, K., Takenaka, S., Norie, M., Martha, V. M., Maryam, K. F., et al. (2010). Structure-function relationships of inhibition of human cytochromes P450 1A1, 1A2, 1B1, 2C9, and 3A4 by 33 flavonoid derivatives. Chem. Res. Toxicol. 23, 1921-1935. doi: 10.1021/tx100286d

Shoskes, D. A., Zeitlin, S. I., Shahed, A., and Rajfer, J. (1999). Quercetin in men with category III chronic prostatitis: a preliminary prospective, double-blind, placebo-controlled trial. Urology 54, 960-963. doi: 10.1016/S0090-4295(99) 00358- 1

Siddiqui, I. A., Shukla, Y., Adhami, V. M., Sarfaraz, S., Asim, M., Hafeez, B., et al. (2008). Suppression of NFkappaB and its regulated gene products by oral administration of green tea polyphenols in an autochthonous mouse prostate cancer model. Pharm. Res. 25, 2135-2142. doi: 10.1007/s11095-008-9553-z

Smeds, A. I., Eklund, P. C., and Willfor, S. M. (2012). Content, composition, and stereochemical characterization of lignans in berries and seeds. Food Chem. 134, 1991-1998. doi: 10.1016/j.foodchem.2012.03.133

Tamler, R., and Mechanick, I. J. (2007). Dietary supplements and nutraceuticals in the management of andrologic disorders. Endocrinol. Metab. Clin. North Am. 36, 533-552. doi: 10.1016/j.ecl.2007.03.005

Tarique, H., Bie, T., Yulong, Y., Francois, B., Tossou, M. C. B., and Rahuu, N. (2016). Oxidative stress and inflammation: what polyphenols can do for us? Oxid. Med. Cell. Longev. 2016:7432797.

Teiten, M. H., Reuter, S., Schmucker, S., Dicato, M., and Diederich, M. (2009). Induction of heat shock response by curcumin in human leukemia cells. Cancer Lett. 279, 145-154. doi: 10.1016/j.canlet.2009.01.031

Tsao, R. (2010). Chemistry and biochemistry of dietary polyphenols. Nutrients 2 , 1231-1246. doi: 10.3390/nu2121231

Udensi, K. U., and Paul, B. T. (2016). Oxidative stress in prostate hyperplasia and Carcinogenesis. J. Exp. Clin. Cancer Res. 35, 139. doi: 10.1186/s13046-0160418-8

Vasundev, V. (2006). Fundamentals of Biochemistry. Textbook of Biochemistry, 2nd Edn. New Delhi: Jaypee Brothers Medical Publishers Pvt. Ltd.

Vitrac, X., Moni, J. P., Vercauteren, J., Deffieux, G., and Mérillon, J. M. (2002). Direct liquid chromatography analysis of resveratrol derivatives and flavanonols in wines with absorbance and fluorescence detection. Anal. Chim. Acta 458, 103-110. doi: 10.1016/S0003-2670(01)01498-2

Yang, A., Ren, G., Tang, L., and Jiang, W. (2009). Effects of soy bean isoflavone on inhibition of benign prostatic hyperplasia and the expressions of NO and NOS of rats. Wei Sheng Yan Jiu 38, 172-174.

Yang, C. S., and Pan, E. (2012). The effects of green tea polyphenols on drug metabolism,". Expert Opin. Drug Metab. Toxicol. 8, 677-689. doi: 10.1517/ 17425255.2012 .681375

Yang, S. J., and Lim, Y. (2014). Resveratrol ameliorates hepatic metaflammation and inhibits NLRP3 inflammasome activation. Metab. Clin. Exp. 63, 693-701. doi: 10.1016/j.metabol.2014.02.003

Zhang, W., Wang, X., Liu, Y., Tian, H., Flickinger, B., Empie, M. W., et al. (2008). Effects of dietary flaxseed lignan extract on symptoms of benign prostatic hyperplasia. J. Med. Food 11, 207-214. doi: 10.1089/jmf.2007.602

Zhou, J., Jiumao, L., Xu, W., Xiaoyong, Z., and Yuqing, Z. (2010). Qianliening capsule treats benign prostatic hyperplasia through regulating the expression of sex hormones, estrogen receptor and androgen receptor. Afr. J. Pharm. Pharmacol. 6, 173-180. doi: 10.5897/AJPP11.547

Conflict of Interest Statement: The authors declare that the research was conducted in the absence of any commercial or financial relationships that could be construed as a potential conflict of interest.

Copyright (c) 2017 Eleazu, Eleazu and Kalu. This is an open-access article distributed under the terms of the Creative Commons Attribution License (CC BY). The use, distribution or reproduction in other forums is permitted, provided the original author(s) or licensor are credited and that the original publication in this journal is cited, in accordance with accepted academic practice. No use, distribution or reproduction is permitted which does not comply with these terms. 